\title{
Education talkback: Television for interactive learning
}

\author{
Tony Dean \\ Western Australian Ministry of Education
}

\begin{abstract}
The unique partnership between the Ministry of Education in Western Australia and the Golden West Network enables educational broadcasts to be transmitted live from Perth via satellite to the whole State. Using telephone talkback techniques, the Ministry is able to emulate the satellitebased communication systems of such agencies as the Knowledge Network in Canada, but with the important distinction of using the public airwaves rather than a private network. This paper reports on the first series of live, interactive programs broadcast by the Ministry in 1987.
\end{abstract}

In his book, July 20, 2019: A Day in the Life of the 21st Century, (Grafton, NY, 1987) Arthur C Clarke describes how John Stanton spends his evening in his home study, which has been equipped for teleconferencing, taking part in a teleclass. He is able to put questions to his teacher who is sitting 1000 $\mathrm{km}$ away in a university television studio. The teacher appears in his home as a life-sized 3D holographic image.

We may well have to wait until the 21st century to see holographic teachers appear in our homes. However, the idea of using communications technology for learning at a distance is very much a product of the latter half of the 20th century. The Schools of the Air in Australia are perhaps the earliest and best known examples. The Open University in the UK popularised the concept of using television for learning at home, and in North America, communications satellites have spawned various systems of video and audio conferencing for teaching and learning. 
In Australia, the AUSSAT satellite is now providing similar opportunities for educational innovation. In May and June 1987, the Ministry of Education in WA conducted a series of experimental live, interactive television programs entitled Education Talkback which were broadcast throughout WA via a combination of satellite and terrestrial means The programs were designed to assess the feasibility of using one way video/two way audio teleconferencing for educational purposes. Telephones were used by viewers to "talk back" to the program presenters during each broadcast. Similar trials have been conducted in Queensland using a system called Q Net, and in NSW there are plans to use Sky Channel to beam TAFE courses, in such subjects as bar service and hotel management, into licensed clubs and hotels. However, whereas these two examples employ closed-circuit or "narrowcast" distribution systems, the Western Australian programs were broadcast on the public airwaves, using an existing commercial television channel.

\section{The background}

In 1984, the then Education Department of WA and four Perth tertiary institutions began broadcasting educational programs on the Golden West Network, a commercial television service operating from Bunbury and covering most of the non-metropolitan south-west region of WA. GWN offered free broadcast time on weekdays between 9.30 and $11.30 \mathrm{am}$, and up to four hours on Saturday mornings. The service, known as ED TV, was co-ordinated by the Education Department's Audio-Visual Branch, and consisted of programs which the various institutions had either produced themselves or for which they had acquired the broadcast rights. These included curriculum-related programs for classroom use, teaching programs for distance education students, and information programs for the general public.

In 1985, GWN was awarded the first licence in Australia to operate a Remote Commercial Television Service (RCTS), a satellite based service which would extend commercial television to all parts of WA without an existing commercial TV service. Subsequently, GWN acquired the only other two rural commercial TV stations in WA, and so by the time the RCTS service commenced in October 1986, GWN had extended its network to include the entire non-metropolitan area of Western Australia, the largest single commercial television service area anywhere in the world.

GWN viewers receive the service either via a normal terrestrial signal or direct from the satellite. In most major population centres the satellite 
signal is received and re-broadcast on a low-powered transmitter. Smaller and more remote communities need their own individual satellite reception dishes, costing around $\$ 2000$. The Perth metropolitan area is excluded from receiving RCTS, because it would compete with existing commercial services. However, educational users have been granted exemption from this restriction, and educational institutions can install their own satellite dishes. In the meantime, negotiations are continuing with Perth commercial TV operators and the SBS, with a view to extending the Ed-TV service terrestrially into the metropolitan area.

\section{The broadcasts}

Education Talkback was designed as a series of programs which would combine conventional professional television production techniques with the interactivity and spontaneity of a live teleconference. The Ministry of Education's television studio in Perth was connected via microwave and broadband bearer to GWN in Bunbury, and a toll-free 008 telephone number was installed, to facilitate calls from viewers. The format of the six programs in the series was a studio panel discussion, including some prerecorded video segments and followed by questions and comments from viewers. For continuity purposes, the same anchorperson, Peter Scharf, and the same studio set were used for all six programs.

The first program, Science is Fun, was intended for remote secondary students studying by correspondence through the Distance Education Centre. It included demonstrations of various science experiments which would otherwise be unavailable to them, and was designed to encourage their interest in further studies in science. Instead of a studio panel, Peter was accompanied by a small audience of students from two local Perth high schools. Questions and comments from this studio audience were used to supplement telephone questions from viewers.

Program 2, Channel Science, and Program 5, The Unit Curriculum, were both specifically designed as professional development programs for teachers, about changes occurring to the secondary school curriculum in WA. Program 3, New Developments in Catholic Education, was presented by the Catholic Education Office as an information program for the general public. Program 4, Breaking Out-A True Life Adventure, was aimed at teenage girls and their parents, and was designed to encourage them to consider a broader range of course and career options. The last program, Early Literacy, was intended for teachers and parents of junior primary children. 
Most of the programs were thus designed either with a dual audience in mind, or with the knowledge that they would attract an additional or secondary audience beyond the specified target group. According to a recent market survey conducted by GWN, Ed-TV programs for schools attract audiences of up to 6000 viewers in the wider community, in addition to the intended school-based audience. The very nature of broadcast television results in an unintended yet interested casual audience of adults beyond whatever specific special-interest group has been identified for a particular broadcast. This phenomenon has both positive and negative aspects. Television can act as a window for the general public to observe educational activities and resources which would otherwise remain inside the walls of the classroom. The fact that they may not fully understand everything they see and hear can be considered to be off-set by the positive attitude towards schools and education in general which such broadcasts may foster. On the negative side, the presence of this secondary audience tends to act as a distraction from the original intention of some programs. For example, in those programs primarily aimed at teachers, for whom a degree of prior knowledge of the topic could be assumed, a certain amount of time was spent explaining the background to the topic, so that the rest of the program would make more sense to a casual viewer.

This duality of purpose also affected the quality of the interaction between the audience and the program presenters. Since some programs invited questions and comments from the general public, there were several instances of individuals phoning with questions of a personal or atypical nature, which would have been of little interest to a wider audience. In order to ensure that questions of broad general interest were asked the program producers organised a number of pre-arranged questions with viewers in advance. This not only allowed each program to stay "on course", but it also acted as an insurance against a shortage of genuine callers during the interactive section of the program. As it turned out, there were less calls than expected during the first two programs, possibly due to the fact that they were designed for a relatively small and specific audience, who were unused to the concept of using the telephone during a TV program. Later programs in the series attracted increasing numbers of callers, possibly because the topics appealed to a wider audience, and perhaps because some viewers had watched earlier programs and had overcome their initial reticence.

The need to organise "Dorothy Dix"-type questions in advance illustrates a dilemma inherent in the whole series, namely, to achieve a sensible balance between high quality television and genuine interaction between presenters and viewers. The more pre-arranged questions were 


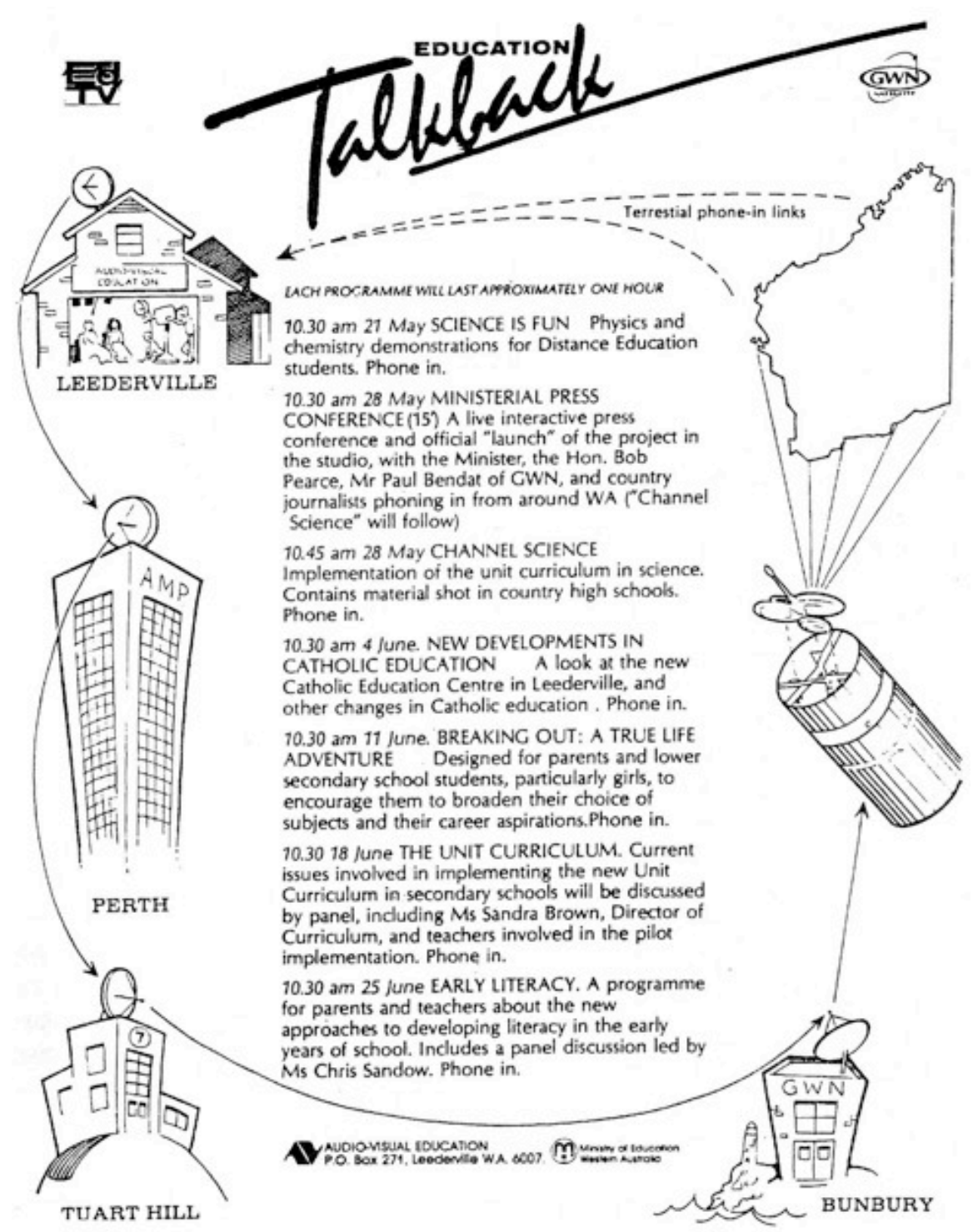


incorporated into each program, the less opportunities would remain for spontaneous questions and comments. On the other hand, it could be argued that the pre-arranged questions anticipated the most likely questions from the audience, and that even though many viewers could not ask a question themselves, they would have heard someone else ask a similar question, and would thus feel some sense of corporate belonging with the wider audience.

\section{Technical considerations}

The initial problem to overcome was to establish a link between the Ministry's television studio in the Perth suburb of Leederville, and the GWN studios in Bunbury, from where the signal is transmitted on the terrestrial network, as well as beamed up to the satellite. This was eventually achieved through the temporary installation of a microwave transmitter, which sent the signal to the top of the AMP building in Perth, where it was connected into another microwave transmitter owned by Channel 7. The signal was then sent to the Channel 7 studios in Tuart Hill, where it was patched into a Telecom broadband bearer, which could then be switched to send the signal to Bunbury.

The telephone talkback component of the programs consisted of three telephones in the studio control room: an incoming 008 telephone, and two independent outside lines, capable of STD, which were operated by two telephone producers. An incoming call would be received on the 008 number, and the caller's name, number and the nature of their question would be recorded. At an appropriate time later in the program, the caller would be phoned back on one of the other lines, meanwhile their name and location would be typed on a caption generator and would appear on a small monitor built into the desk in front of the presenter. This allowed the presenter to introduce the caller, who would then be switched through, and whose voice could be heard by the panelists via a loudspeaker in the studio. At the same time, one of six colour slides depicting various regions of WA was put on the screen, superimposed with the name and location of the caller.

Apart from the special telephone arrangements, the programs were designed as conventional multi-camera studio productions, with some pre-recorded segments shot on location. The fact that the programs were broadcast live added an extra dimension to the productions, and highlighted the need for careful preparation and rehearsal. Each program involved a one hour rehearsal both for crew and talent the day before the broadcast. As the series progressed, the pre-production process became more streamlined, as the crew became more comfortable with their respective roles. However, partial rehearsals were still held, mainly because the panel members changed with each program. 


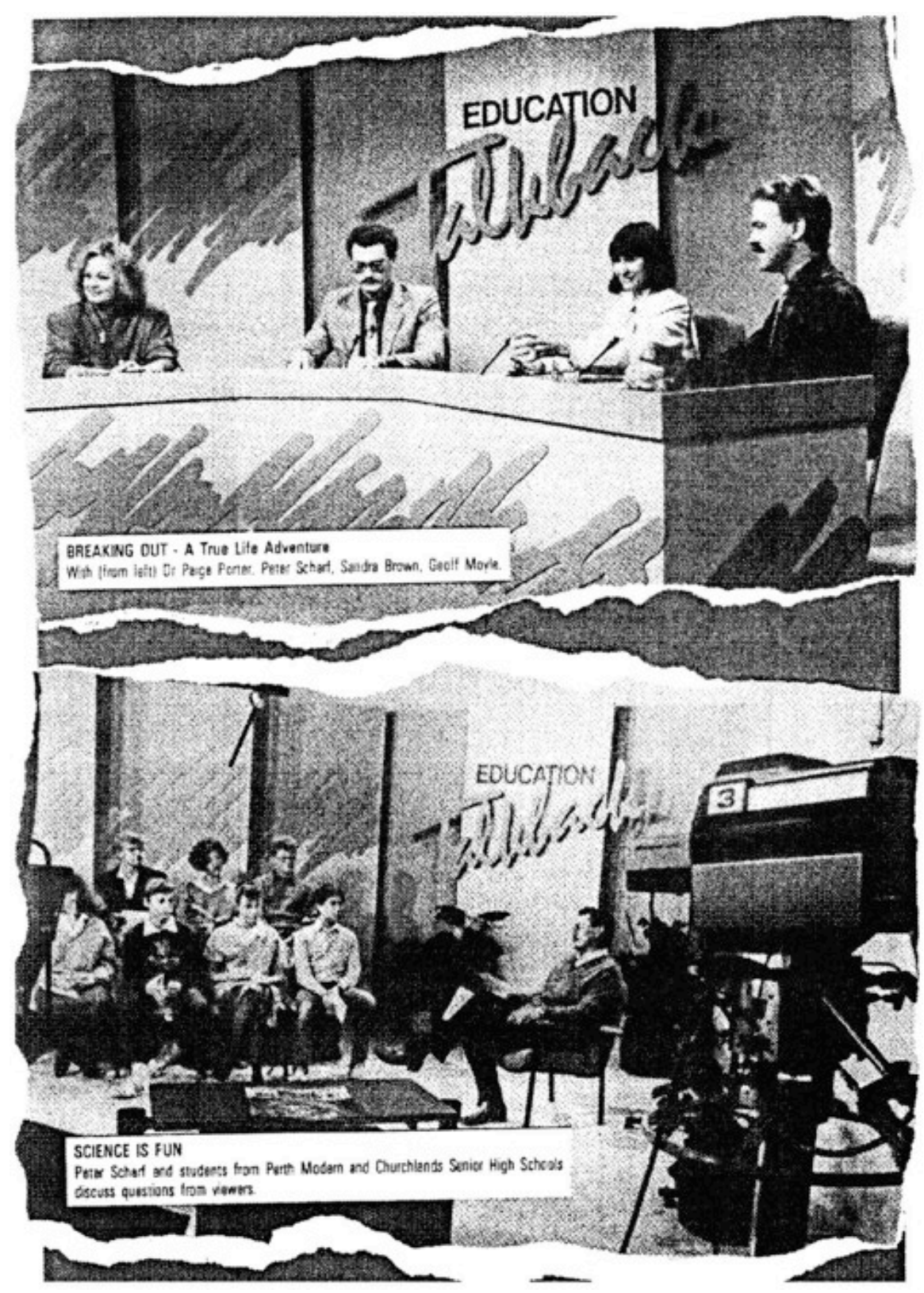


Two factors contributed to the success of the panel discussions. Firstly, the series used a presenter for all six programs who was able to chair the discussions expertly, as well as hold together the various planned and unplanned elements of a live broadcast. Secondly, all the panelists were able to overcome any initial signs of tension or nervousness during the rehearsal stage, and performed smoothly and with confidence during the actual broadcasts. However it has been suggested that panelists for future broadcasts be subjected to a more rigorous audition and selection process, as it cannot be expected that a confident public speaker would automatically adapt to television presentation.

Up to 16 crew members worked behind the cameras in the studio for each broadcast (see Appendix 1). This partly reflects the additional staff required to operate the telephones and to communicate with the presenter via a caption generator, as well as the producer's overall intention to make each broadcast as professional as possible. This number could possibly be reduced to 12 , if live broadcasting/teleconferencing were to continue on a regular basis.

\section{Evaluation}

Staff and time constraints prevented any rigorous, analytical evaluation of the series from being carried out. However, senior production staff participated in a formative evaluation by meeting together weekly after each program, and modifying various production elements as a result of the experience gained with each broadcast. Secondly, a summative evaluation of audience response was undertaken at the end of the series. Thirty-five randomly selected viewers of individual programs in the series were interviewed either face-to-face or by telephone with a series of prepared questions (see Appendix 2). Whilst their feedback was largely spontaneous and anecdotal in nature, there were several common threads which emerged in their responses.

All respondents indicated that they found the programs either of great value or of some value, and that they would be interested in watching other live interactive programs. Topics suggested for future broadcasts included various distance education subject, particularly maths and science, programs for parents about education and child development, issues concerning Aboriginal education, the special needs of country parents, and a wide variety of professional development topics for teachers, including school development planning, managing student behaviour, community participation in schools, and curriculum development. 
Most respondents were pleased with the style and presentation of the programs, and appreciated the clarity and conviction of the panelists, although some viewers suggested that the inclusion of panelists with more differing points of view on each topic would have encouraged a more dynamic interchange. Community members seemed particularly appreciative of the programs, and indicated that there was a large audience of parents, mainly as a result of promotion of the programs by schools.

Most viewers who had phoned with a question or comment during the broadcasts expressed satisfaction with using the phone as a means of communicating with the panel, even though some had to wait up to 15 minutes before taking the opportunity to put their question. Some callers were critical of the fact that they did not have the chance to put a supplementary question or comment to the panel. As it was, the telephone producers asked most callers before putting their call through whether they wanted to ask a supplementary question. If they said yes, they would be left on the line; it the answer was no, or they were undecided, the telephone producer would ask the caller to hang up soon after the question was asked. Theoretically, the caller would be able to hear the remainder of the answer to his or her question on the TV, although this was a problem for some callers where the telephone was situated some distance from the TV. From the point of view of the producers, it was desirable to terminate a call as soon as possible, to give them enough time to line up the next call, and to give as many other callers as possible the opportunity to speak. Ultimately, it was the program presenter who had to decide how long to allow discussion of a particular question, and whether to stay with a caller or move on to the next one. It was inevitable, therefore, that some callers would be dissatisfied, if they felt that their question was not considered in sufficient depth by the panel.

The survey attempted to identify any physical constraints on audience use of the programs. Home based viewers who called with questions generally had no problems using the telephone while watching the program. Some schools, however, found it a problem to provide a phone within reasonable proximity of the TV.

Those viewers who watched but did not ask a telephone question nominated a variety of reasons for not doing so. The most common were:

- too shy; unused to doing it.

- couldn't get through; technical difficulties.

- familiar with the topic; nothing to offer. 
Several other viewers lodged questions with the telephone producers, but time ran out before they had the opportunity to put the question to the pane. The broadcast time of 10.30 am to 12 noon was acceptable to the home based viewers, although obviously the audience sample did not include potential viewers who were unavailable at that time of day. School audiences were divided about the suitability of the timeslot. Viewing the programs live was obviously limited to those teachers who were free or who had been relieved of teaching duties at that time. Some claimed that the programs should run no longer than one hour. Many schools indicated that they were time -shifting the programs and replaying them for their staff after school. This obviously removed their opportunity for audience participation, but allowed larger numbers of staff to view the programs, and to discuss the issues raised amongst themselves.

The question remains, as to whether the added dimension of live interactive broadcasting was warranted, compared with conventional prerecorded program production. If the majority of viewers timeshifted the program to suit themselves, would a normal pre-recorded program have been of equal value or interest? A conventional program would theoretically have made better use of the available program time, through the use of video editing and the avoidance of any irrelevant or uninteresting issues. It could be argued however, that the additional production time involved in editing would offset any cost savings in not having to broadcast the program live. Another option would be to broadcast a pre-recorded TV program, followed by an audio only teleconference for those groups or individuals who wanted to discuss it and pursue the issues in greater depth. This format has been successfully used in professional development programs for special interest groups of limited numbers, when the audience was able to meet together at a number of specific locations, such as direct education offices.

Whilst there are obvious limitations on the quantity and quality of audience interaction possible in the Education Talkback series, the balance of evidence suggests that it is a viable and worthwhile format for certain specific purposes. It needs to be remembered that in any large group meeting, the interaction between presenters and audience is also limited. In comparing a conventional face-to-face meeting with Education Talkback series, it could be concluded that the intervention of the telephone and television media between presenters and audience did not significantly detract from the interaction which occurred. 
The intangible benefits of interactive broadcasting are best illustrated by the frequent comments which occurred in the audience survey, along the lines of:

It's nice to know people in head office are listening to what we think .. it's great to hear other people facing up to the same problems that we have.

Since the programs were designed primarily for a non-metropolitan audience, the fact that the needs of country people were being addressed, and that country people had the opportunity to be heard by others was obviously appreciated. Therefore, although the opportunities for interaction were limited, the audience participation nevertheless appeared to foster a sense of corporate identity among the wider audience and a more positive attitude towards the subject under discussion, which a conventional pre-recorded program may not have done Also, audience interest in a live program tends to be greater, because of the sense of anticipation and uncertainty as to what will happen next, which is aroused by watching a live event, rather than a prepared and carefully edited program.

\section{Conclusions}

The series appears to have established the value of live interactive broadcasting for broad community education purposes as well as for the professional development teachers. There are obvious logistical problems in getting large numbers of teachers to watch a one off program during school hours, but, if properly planned, a live broadcast or series of broadcasts could be a valuable component of a larger professional development initiative, particularly if it was integrated into staff seminars in schools.

The series did not sufficiently examine the potential of live interactive broadcasting for direct teaching purposes, as only two of the programs were designed for use by students. The extent to which live broadcasts can be incorporated into distance education courses deserves further investigation and trialing. Overseas experience, particularly of such agencies as the Knowledge Network in British Columbia, indicates live interactive television can be a very effective and successful medium for adult education, but it cannot be assumed that this experience translates directly to primary and secondary education in WA. As Education Minister Bob Pearce pointed out when officially launching the Education Talkback series, "television is a very powerful medium... There is certainly considerable scope for television and teleconferencing to provide sequential support for courses which are offered in various ways...but the best educational package seeks to combine the various media, rather than isolate one in preference to the others." 
The unitization of the secondary school curriculum in WA, the growing pressure on schools, particularly on smaller rural schools, to offer a comprehensive range of courses, and the increasing number of students staying on in rural school to complete further studies by correspondence or "mixed-mode" study, are all trends which could be supported by the innovative use of communications technology. Hopefully Education Talkback will have served as a catalyst to explore this potential further.

\section{Acknowledgements}

This report would not be complete without acknowledging the work of Peter Scharf, who was not only series presenter but was also instrumental in solving the technical difficulties of live broadcasting; series director Ross Hutchens; technical director Steve Pearce; and the numerous production and education staff at Audio-Visual Education who worked on the series. The Ministry of Education was also assisted by NEC Australia, TVW Channel 7, Telecom Australia, and the Golden West Network.

\section{Appendix 1}

Education Talkback - Credits

Director: Ross Hutchens

Presenter: Peter Scharf

Producer: Howard Worth

Technical Director: Steve Pearce

Executive Producer: Tony Dean

Phone Producers: Ralph Gerrard, Ken Miller

Director's Assistant: Jinette Colwill

Vision Mixer: Cathy Hollingworth

Floor Manager: Mike Nicholls

Production Assistant: Anna Pedulla

Editor: George Karpathakis

Graphics: Steve Mason

Set: Helen Smith,Vince Kemp

Make-up: Jan Piantoni

Vision Control Mark Barrett

Audio: John Van Rullen, Colin Lutter

Lighting Cameraman: Ray Grenfell

Camera Operators: Alan Coleman, Peter Strain 


\section{Appendix 2}

Education Talkback - Audience Telephone Survey

1. Which program(s) did you watch?

2. Did you find the program of-great value; some value; little value?

3. Would you be interested in watching other live interactive programs?

4. If $\mathrm{YES}$, on what topics?

5. Did you ask a question during the broadcast?

6. If $\mathrm{NO}$, why not?

7. If YES -

(a) where you satisfied with using the telephone as a means of asking questions or making comments?

(b) did you have to wait long to ask your question; if so, was this a problem?

(c) Was it a distraction having to hang up after asking the question?

(d) Was it difficult ringing up whilst watching TV?

8. If it was possible to broadcast live programs at other times, what times would you prefer?

9. Would you like to comment on the design of the program and style of presentation?

10. Any other comments?

Author: Tony Dean is Senior Education Officer with the Ministry of Education's Curriculum Services Branch. He is the coordinator of the EDTV educational broadcasting service on the Golden West Network, and has served as both State and National President of the Australian Society for Educational Technology. This paper is a report on an experimental series of interactive educational television programs, broadcast via satellite throughout Western Australia in May and June, 1987.

Please cite as: Dean, A. (1988). Education talkback: Television for interactive learning. Australian Journal of Educational Technology, 4(1), 46-58. http:/ / www.ascilite.org.au/ajet/ ajet4/dean.html 